\title{
Political Ideology and the Outbreak of COVID-19 in the United States
}

\author{
Author: D. Rosenfeld ${ }^{1 *}$
}

\author{
Affiliations: \\ ${ }^{1}$ Department of Psychology, University of California, Los Angeles. \\ *Correspondence to: rosenfeld@g.ucla.edu
}

\begin{abstract}
At the state level within the United States, did political ideology predict the outbreak of the novel coronavirus (COVID-19)? Throughout March 2020, the United States became the epicenter of the COVID-19 pandemic, recording the most cases of any country worldwide. The current research found that, at the state level within the United States, more conservative political ideology predicted delayed implementation of stay-at-home orders and more rapid spread of COVID-19. Effects were significant across two distinct operationalizations of political ideology and held over and above relevant covariates, suggesting a potentially unique role of political ideology in the United States' COVID-19 outbreak. Considering political ideological factors may offer valuable insights into epidemiological processes surrounding COVID-19.
\end{abstract}

One Sentence Summary: Conservative political ideology may have delayed protective policy implementation and promoted spread of COVID-19 in the U.S.

Main Text: Throughout March 2020, the United States became the epicenter of the COVID-19 pandemic. Despite declaring a state of national emergency on March 13 when the prevalence of COVID-19 remained low in the U.S. at 1,264 cases (1-2), the U.S. proceeded to experience a rapid outbreak of COVID-19 during the following month, exceeding over 400,000 cumulative cases by April 10 (2). Politicization of COVID-19 in the U.S. may have played a unique role in the virus's proliferation, with conservatives feeling less concerned about COVID-19 than liberals as a result of President Donald Trump's downplaying the pandemic's urgency (3). This, in turn, resulted in divergent social norms for conservatives and liberals, with COVID-19 being seen as less threatening among conservatives and more threatening among liberals (3). These politicized perceptions of COVID-19 may have influenced how individual U.S. states responded to the pandemic. The current research specifically asked the following question: At the state level within the U.S., did political ideology predict the outbreak of COVID-19?

Across the 50 U.S. states, variances in political ideology are substantial (4). Theoretical perspectives from social psychology suggest that a having a more conservative political ideology could have delayed a state's COVID-19 protective policy implementation and promoted spread of COVID-19 via processes of motivated reasoning and moral cognition. Through motivated reasoning, individuals are intrinsically — and often unconsciously_-biased to confirm their preexisting beliefs and to evaluate evidence with self-serving partiality (5). Holding a politically conservative ideology may have promoted selective interpretation of COVID-19 evidence to support the in-group norm (upheld by President Trump) that the COVID-19 outbreak was under adequate control and of little urgent concern. Political-ideological differences in moral cognition may have coupled with motivated reasoning to decrease the perceived need for COVID-19 protective policy (e.g., stay-at-home orders) and individual behavior (e.g., social distancing) within conservative states. Compared to liberals, conservatives more strongly emphasize moral values of respect for authority and loyalty to social in-groups (6). With President Trump's administration - as the authority of political conservatism in the U.S. - downplaying the urgency 
of COVID-19, conservative state policy makers and residents may have been morally motivated to trust that COVID-19 is of little urgent risk, to support the COVID-19 positions endorsed by President Trump, and in turn to practice fewer protective individual behaviors. These factors may have delayed the implementation of stay-at-home orders and promoted the spread of COVID-19 within more conservative states.

The aim of the current research was to investigate the role of political ideology in the outbreak of COVID-19 in the U.S. at the state level. The first specific aim was to identify whether a state's political ideology predicted the date at which the state implemented a stay-athome order. The second specific aim was to identify whether a state's political ideology predicted the rate at which COVID-19 spread within that state three weeks into the pandemic. Throughout tests of these aims, three covariates were controlled for to rule out potentially confounding variables that could covary with state political ideology and drive these outcomes: 1) the total population of each state, 2) the population density of each state, and 3) the relative accumulated prevalence of COVID-19 cases in each state (i.e., the number of accumulated cases per million residents) on March 31, 2020. In predicting the date at which states implemented a stay-at-home order, the rate at which COVID-19 was spreading three weeks into the pandemic was controlled for. In predicting the rate at which COVID-19 was spreading, date of stay-athome order implementation was controlled for. Adjusting on these covariates facilitated more precise tests for causal inference as to whether a state's political ideology may have uniquely driven COVID-19 policy and spread.

It was hypothesized that, over and above covariates, more conservative states - as indicated by a) a higher prevalence of self-identified conservatives relative to liberals and b) a higher prevalence of residents who voted for Donald Trump in the 2016 U.S. presidential election-would implement a stay-at-home order at a later date and report a more rapid growth in COVID-19 cases from March 31, 2020, through April 10, 2020. March 31 was selected as the start of this interval because it marked approximately the average date on which U.S. states implemented a stay-at-home order (7). April 10 was selected as the end of this interval given that it marked the passing of one month since the World Health Organization declared COVID-19 a pandemic (8) and four weeks since the U.S. declared a state of national emergency (1). All confirmatory analyses involved ordinary least squares regressions, with a separate regression conducted to test each of the four distinct hypotheses. Data were obtained from recent reportings by the Center for Disease Control (9-10), Gallup (4), Politico (11), US Census State Population Estimates (12), and the Kaiser Family Foundation (7). All data and code for the current research are publicly available at https://osf.io/be3vf/?view_only=044a25689b9b4f08a7b88bde11e37c93.

Support emerged for all four hypotheses, with state political ideology predicting date of stay-at-home order implementation and spread of COVID-19 within the state, over and above the effects of all covariates. First, higher prevalence of self-identified conservatives relative to liberals in a state strongly predicted later date of implementing a stay-at-home order, $\beta=0.70, p$ $<0.001$ (see Fig. 1). Second, higher prevalence of residents who voted for Donald Trump in the 2016 U.S. presidential election within each state strongly predicted later date of implementing a stay-at-home order, $\beta=0.52, p<0.001$ (see Fig. 2). Third, higher prevalence of self-identified conservatives relative to liberals in a state predicted more rapid growth of COVID-19 cases within the state from March 31 through April 10, $\beta=0.16, p=0.01$. Fourth, higher prevalence of residents who voted for Donald Trump in the 2016 U.S. presidential election within each state 
predicted more rapid growth of COVID-19 cases within the state from March 31 through April $10, \beta=0.12, p=0.03$.

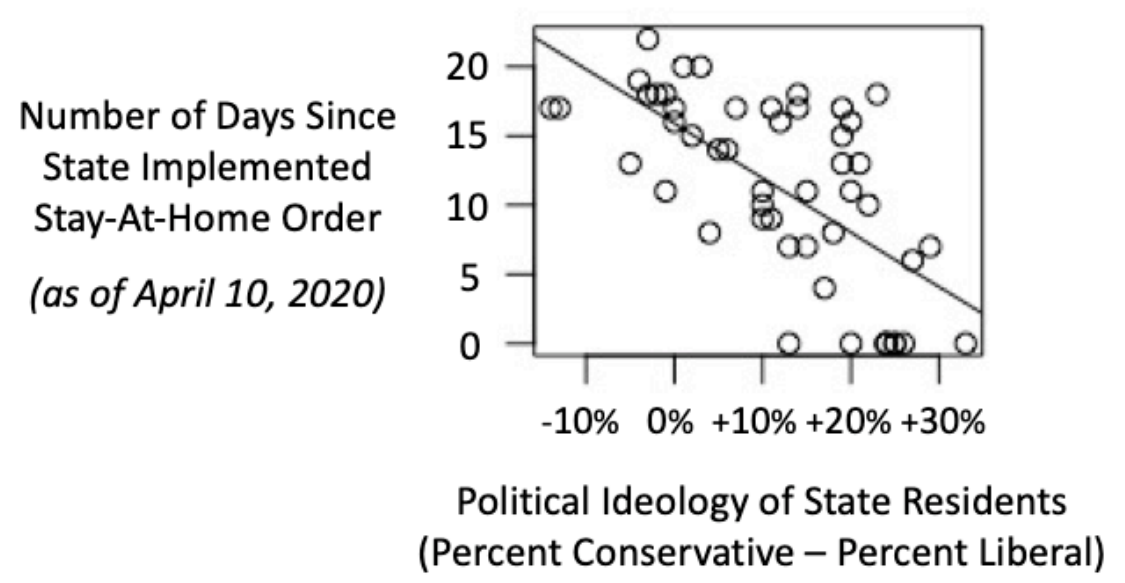

Fig. 1. Relationship between the prevalence of self-identified conservatives relative to liberals in each state and the number of days since each state implemented a stay-at-home order, as of April 10, 2020. Zero-order correlation coefficient of $r=-.66(p<0.001)$ indicates a strong relationship whereby more conservative states implemented stay-at-home orders at later dates.

Number of Days Since State Implemented Stay-At-Home Order

(as of April 10, 2020)

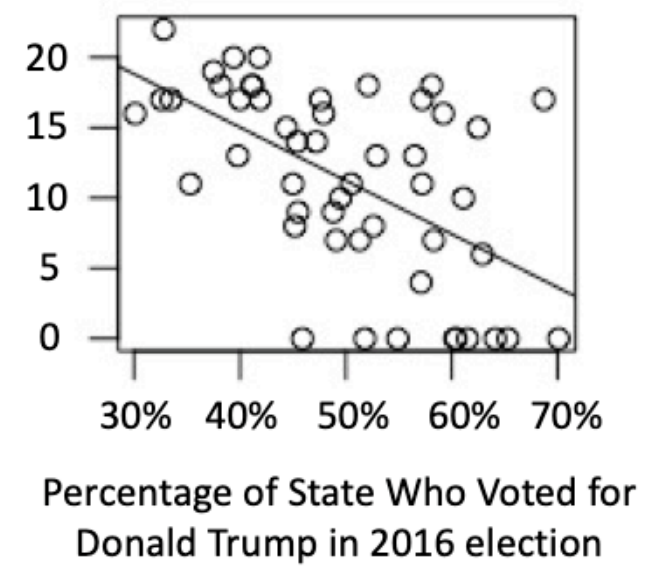

Fig. 2. Relationship between the percentage of residents in each state who voted for Donald Trump in the 2016 U.S. presidential election and the number of days since each state implemented a stay-at-home order, as of April 10, 2020. Zero-order correlation coefficient of $r=$ $-.57(p<0.001)$ indicates a strong relationship whereby more pro-Trump states implemented stay-at-home orders at later dates.

These findings suggest that the political ideology of states in the U.S. predicted what measures states took to reduce the spread of COVID-19 as well as how rapidly new cases of COVID-19 spread within states from March 31 through April 10, 2020. Effects of both political 
ideology indices held significant over and above states' total populations, population densities, and incidences of COVID-19 prior to March 31. Beyond controlling for these factors, political ideology offered unique value for predicting a) the timing of stay-at-home order implementation over and above effects of COVID-19's growth rate within each state and b) the growth rate of COVID-19 within each state over and above that state's timing of stay-at-home order implementation. Although true causality cannot be inferred from these correlational data, the highly controlled nature of the performed regression models suggests the potential for causal mechanisms. Specifically, it may be that politically conservative ideologies delayed the implementation of stay-at-home orders and promoted the proliferation of new COVID-19 cases in the U.S.

One theorized mechanism underlying the effects of state political ideology on COVID-19 outcomes is motivated reasoning, or the bias to confirm one's preexisting beliefs and to evaluate evidence with self-serving partiality (5). Other mechanisms may relate to politicized perceptions of morality, with conservatives emphasizing moral values of respect for authority and loyalty to social in-groups to greater extents than do liberals $(6)$ - in the current context, these moral values may have promoted respect for President Trump's views on COVID-19 and feeling a moral obligation to support those views oneself. Together, these social-psychological factors may have led conservatives to underestimate the risk of COVID-19 and to undervalue the urgency of preventative policies (e.g., stay-at-home orders) and individual behaviors (e.g., social distancing).

Ultimately, the current research suggests that more conservative political ideology predicted delayed implementation of stay-at-home orders and more rapid growth of COVID-19 cases by state within the U.S. In considering discrepant COVID-19 pandemic outcomes across countries and territories within and beyond the U.S., giving attention to political ideological factors may offer valuable insights into epidemiological processes.

\section{References and Notes:}

1. White House, Proclamation on declaring a national emergency concerning the novel coronavirus disease (COVID-19) outbreak. White House, https:/www.whitehouse.gov/presidential-actions/proclamation-declaring-nationalemergency-concerning-novel-coronavirus-disease-covid-19-outbreak/ (2020).

2. World Health Organization, Coronavirus (COVID-19). World Health Organization, https://who.sprinklr.com (2020).

3. S. Kushner Gadarian, S. W. Goodman, T. B. Pepinsky, Partisanship, Health Behavior, and Policy Attitudes in the Early Stages of the COVID-19 Pandemic. Health Behavior, and Policy Attitudes in the Early Stages of the COVID-19 Pandemic (2020).

4. Gallup, Americans' political ideology by state in 2017. Gallup, https://news.gallup.com/file/poll/226775/2018_02_06_Ideology $\% 20$ by $\% 20$ State_Graph $\% 20$ 4.pdf (2018).

5. Z. Kunda, The case for motivated reasoning. Psychological Bulletin, 108, 480-498 (1990).

6. J. Graham, J. Haidt, B. A. Nosek, Liberals and conservatives rely on different sets of moral foundations. Journal of Personality and Social Psychology, 96, 1029-1046 (2009). 
7. J. Kates, J. Michaud, and J. Tolbert, Stay-at-home orders to fight COVID-19 in the United States: The risks of a scattershot approach. Kaiser Family Foundation, https://www.kff.org/coronavirus-policy-watch/stay-at-home-orders-to-fight-covid19/ (2020).

8. World Health Organization, WHO Director-General's opening remarks at the media briefing on COVID-19 - 11 March 2020. World Health Organization, https://www.who.int/dg/speeches/detail/who-director-general-s-opening-remarks-at-themedia-briefing-on-covid-19---11-march-2020 (2020).

9. Center for Disease Control, Cases in U.S. Center for Disease Control, https://www.cdc.gov/coronavirus/2019-ncov/cases-updates/cases-in-us.html (2020).

10. Center for Disease Control, Geographic differences in COVID-19 cases, deaths, and incidence - United States, February 12-April 7, 2020. Center for Disease Control, https:/www.cdc.gov/mmwr/volumes/69/wr/mm6915e4.htm?s_cid=mm6915e4_x (2020).

11. Politico, 2016 presidential election results. Politico, https://www.politico.com/2016election/results/map/president/ (2016).

12. US Census State Population Estimates, United States by density 2020. World Population Review, https://worldpopulationreview.com/states/state-densities/ (2020).

\section{Acknowledgments:}

Funding: This research was not supported by any funding.

Author contributions: D.R. was responsible for all aspects of this research.

Competing interests: The author declares no competing interests.

Data and materials availability: All data and code are available via the Open Science Framework at https://osf.io/be3vf/?view_only=044a25689b9b4f08a7b88bde11e37c93. 